\title{
A Team Project that Improves Student Engagement in Large Classes
}

\author{
Karen Ford-Eickhoff \\ University of North Carolina Charlotte \\ Cheryl L. Kane \\ University of North Carolina Charlotte
}

Our university has grown dramatically over the past several years. Although there is much that is good about this growth, it has also generated growing pains. The increase in student enrollment has outpaced the addition of new faculty and classroom space, and this is reflected in the enrollment doubling in one of our department's junior-level courses. We share an innovative team project assignment that has successfully improved the level of engagement of students in this large-class format. Readers will find a thoughtfully designed and thoroughly tested model for improving student engagement in their own large classes.

Keywords: Team Project Assignments, Student Engagement in Learning

\section{INTRODUCTION}

Our university has been growing by leaps and bounds for several years - the number of undergraduate students has grown $40 \%$ in the last decade. Approximately a third of our new undergraduate students are first-generation college students and $44 \%$ are transfer students. About a third of transfer students come to our university with a two-year degree. A recent university report shows our students came from 85 countries and 49 U.S. states, bringing with them great diversity of backgrounds (University of North Carolina Charlotte Office of Undergraduate Admissions, 2018).

Although there is much that is good about this growth, this expansion has brought its share of growing pains as well. Enrollment has outpaced the addition of new faculty and classroom space, and a reflection of this is that our department's junior-level course titled Management and Organizational Behavior now typically enrolls 75-80 students in each section, almost double the typical enrollment just six years ago. All business majors funnel through this course, and students majoring in several nonbusiness areas take the course as well. The course is often one of the first students encounter after completing the general education portion of their coursework. For many students this is one of the first courses they take on a large university campus and is often the first class they have experienced being one of 80 students in the classroom. This is also among the first courses students take in the Belk College of Business, and students often note in student evaluations that this course was a big step up in rigor relative to their courses up to this point. 
This tidal wave of growth combined with the diversity of academic preparation and cultural backgrounds created some challenges. The faculty member teaching the course (referred to as Professor $\mathrm{K}$. hereafter) began to recognize the signs that students were not self-managing the course workload well and felt overwhelmed, specifically in terms of keeping up with the reading required for the course. She also perceived that many students acted like they were anonymous parts of a crowd when they were in a class of 80 students, negatively affecting the students' sense of accountability and need for engagement in class discussions. In reviewing her records, Professor K. found that students typically attended around $80 \%$ of class meetings, typically $20 \%$ of students earned a failing grade on the first exam, and students rarely came to Professor K's office hours until after receiving a failing grade on the first exam. The percentage of students with failing grades in the course at the end of the semester was $11 \%$, and the percentage of students withdrawing from the course before the end of the semester was $6 \%$. Students expressed that they felt buried in a deep hole by mid-term because they had not devoted adequate time outside of class to reading and studying the material and also had not communicated with Professor K. early enough about difficulties they were experiencing.

Professor K., drawing upon her 15 years of experience teaching, set out to address these issues by adding a team project assignment specifically designed to improve the engagement of students enrolled in the course by a) reducing the sense of isolation of individual students and b) increasing the time students spent interacting with the course material. Evidence indicates that this project has improved the engagement of students in this course at our university. An overview of the team assignment before, during, and after implementation is shown in Figure 1. We also address lessons learned during the implementation of the team project assignment. Readers will find a thoughtfully designed and thoroughly tested model for improving student engagement in their own large classes.

\section{FIGURE 1 \\ OVERVIEW OF TEAM ASSIGNMENT BEFORE, DURING, AND AFTER IMPLEMENTATION}

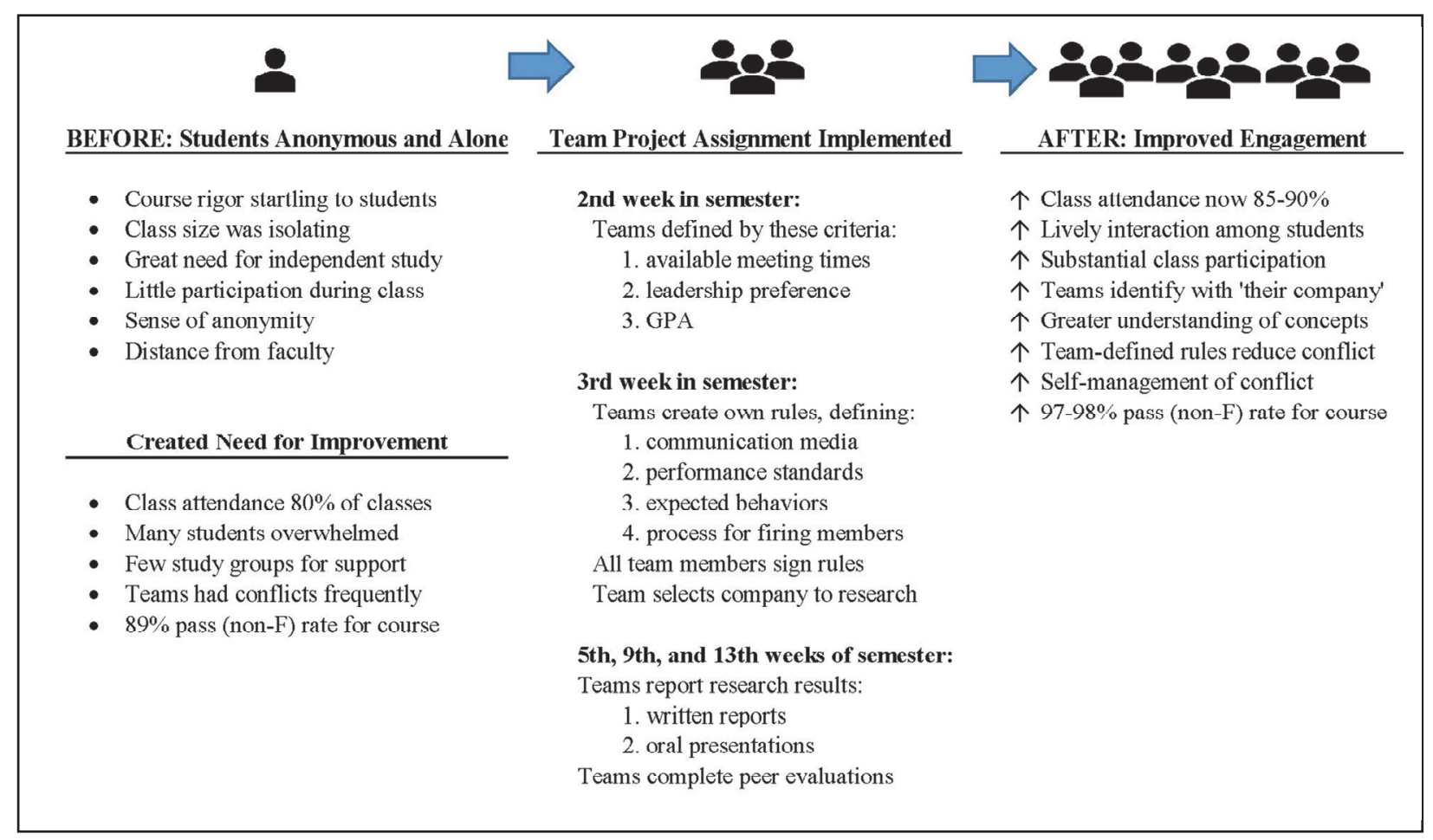




\section{THE COURSE}

The Management and Organizational Behavior course is a required, junior-level business course designed for business majors as they transition from the general education foundation courses to the courses in their chosen business major. At our university, it is taught in a fifteen-week semester and is offered every semester.

Professor K. breaks the semester approximately into thirds with an exam assessing learning at the end of each third. Thirteen topics are covered:

Exam I

- Management performance

- Internal and external environments

- Leadership

- Teamwork

Exam II

- Human resource management

- Planning

- Strategic management

- Organizational structure and agility

- Ethics and corporate responsibility

Exam III

- International management

- Managerial control

- Managerial decision-making

- Motivating for performance

The enrolled students are sophomores and juniors. As noted earlier, this is among the first courses students take in the Belk College of Business so many students do not have established peer relationships with others enrolled in the course. Most of our students commute to campus rather than residing in oncampus dormitories, and most work, sometimes full-time, in addition to taking a full course load. These circumstances may further limit their abilities to effectively network with their classmates outside of class time. Combined with the size of the class, this lack of friendship ties with other students sets up a class room environment that can be quite intimidating for students. The faculty member is literally far away physically in the large classroom setting and may seem unapproachable. Whereas the instructor may have known most if not all students by name in smaller classes before, it is considerably more difficult for instructors to learn 80 students' names per class so this adds to the students' sense of being lost in a crowd. Add to this, it is difficult in a 50- or 75-minute class session to have time for the instructor to interact with individual students. The classroom becomes the setting for a large number of diverse individuals to be together in one place but acting in isolation. It is easy to see why this large classroom environment makes students feel much less comfortable participating in class discussions.

\section{THE TEAM PROJECT}

Five years ago, Professor K. set out to design a course project that would improve the students' engagement in the class even though it is a large-class format. Professor K. particularly wanted to develop a team-based project since she believed students would benefit specifically from working with classmates on the project. The literature has shown that students engaging with course concepts along with others in the classroom team often produces a synergy of understanding that transcends the comprehension of an individual working alone (Brooks \& Ammons, 2003; Curşeu, Schruijer, \& Fodor, 2017; Davison, Mishra, Bing, \& Frink, 2014). Since organizations value job candidates and employees who possess teamwork 
skills such as the ability to gather and share information, solve problems, plan and manage performance relative to goals, and deal with conflict, it is particularly important that classroom activities develop teamwork skills that are transportable to other contexts (Chen, Donahue, \& Klimoski, 2004).

To form teams, students complete a survey at the beginning of the semester utilizing the online CATME software (www.CATME.org) which forms teams based on instructor-selected factors such as the students' schedules, whether they are available for weekend meetings, their GPA, and the students' leadership preferences (Layton, Loughry, Ohland, \& Ricco, 2010). The software also provides a process for peer evaluations based on the Behaviorally Anchored Rating Scale approach to performance appraisals (Loughry, Ohland, \& Woehr, 2014; Ohland, Loughry, Woehr, Bullard, Felder, Finelli, Layton, Pomeranz, \& Schmucker, 2012). Professor K.'s use of this online system supports students in being effective in their team management as well as supporting the efficient use of her time as the instructor in managing the team project throughout the semester. Professor K. announces the teams formed by the CATME algorithm to the class, and the students normally remain in the same teams for the entire semester. Each section of the course typically has 12-14 teams with 5-6 students per team.

Each team selects a publicly-traded company to research from a list that Professor K. provides. Professor K. selects these companies because they are in the news, familiar to students, and have readily available information. Teams select their companies on a first-come, first-served basis during class early in the semester. The students want to select a company they are interested in researching so the company selection process becomes quite competitive and provides an incentive for teams to make their selections sooner rather than later in the semester. Only one team in each section researches any one company from the list so 12-14 companies are covered each semester, providing the students the opportunity to learn about several companies beyond the one their team researched in depth.

Once the teams and companies are assigned, the project centers around the teams researching their company relative to specific topics in the course using current, credible secondary sources. Professor K. arranges for a business reference librarian to guest lecture on accessing credible secondary sources through our campus library resources early in the semester. As noted earlier, these specific topics include Leadership, Human Resources Management, Ethics, Corporate Responsibility, Managerial Decisionmaking, and Motivating Performance that are covered in each third of the semester and tie to the three exams. The teams perform this research into current events to determine how their company implements, uses, adapts to, disrupts (or fails to implement, use, adapt to, or is disrupted by) these specific topics being discussed over the course of the semester.

The teams submit two-page papers summarizing what they find in their research and present their findings in 3-5-minute oral reports. Professor K. allows students to present from their seats in the classroom rather than from the front of the room if they prefer to encourage all team members to participate in the presentations. Each team writes three reports and does three presentations over the course of the semester, addressing the groups of topics that are covered in each third of the semester and on three exams. For example, all teams explore their companies relative to the topics of Leadership and Human Resources Management for the first report early in the semester and then these topics are also tested in the first exam. Three or four teams present each class, and these presentations focus all students' attention on comparing how these companies are impacted by the same things (Leadership for example). All students are encouraged to engage in the discussion by asking questions of the presenting team and offering their own insights in comparing the companies relative to these course topics, and all students take short quizzes after the presentations to reflect their learning in writing as well. The team project assignment helps students develop analytical skills and critical thinking skills by encouraging them to think about whether their company handled an issue correctly and what they think will happen next. To conclude each report, students submit peer evaluations via the online CATME software.

\section{DEALING WITH CONFLICTS}

A major factor in Professor K.'s design of the team project is to give the students authority over managing their team. Professor K. recognized the many benefits of students working in teams on this 
project but also anticipated that working in teams would likely result in conflicts among some students. Professor K. built a process for handling these conflicts into the project, particularly for handling those more extreme situations in which the team wishes to "fire" a person from the team.

The first assignment for teams is to agree upon the team rules. The team rules must include: 1) the acceptable modes of communication, 2) the cycle time for communications, 3) acceptable behavior for participating and producing high-quality work, and 4) a clear path of progressive discipline, including how the team may fire non-performing team members. All team members must sign the rules they have created, signifying their acceptance of the applicability of the rules to their own behaviors and performance.

If a team is having conflicts among team members, Professor K. guides them in the process of resolving these conflicts. Her first question is "what do your rules say?" She asks what specific expectations the offender has violated, how the team has documented these violations, and how the team wants to proceed. If the team decides to fire a team member, the team must craft an e-mail to the offender and carbon copy Professor K. If the offender wants to stay in the course, he or she must then schedule a face-to-face meeting with Professor K., explain the reasons behind being fired, and request to be put on a different team. While maintaining the anonymity of the offender, Professor K. will either plead the offender's case to the class, asking for a team to volunteer to add the offender, or she will privately contact a team to see if those students want to invite the offender to join their team. If a team wants to invite the additional team member to join, Professor K. coaches the team members on interviewing the offender, sharing their rules and expectations, and making a decision. If another team does not want to invite the offender to join, Professor K. will allow the offender to do the project individually without the help of team mates. However, the offenders normally are invited to join another team and in general successfully complete the project after this wake-up call.

Professor K. tries to make these unfortunate situations into a learning opportunity that will benefit all students involved. In addition to her own efforts to guide them through the conflict, she shares campus resources available to students such as free workshops on time management, behavior changes, diplomacy, etc. offered by the Center for Academic Excellence and the Counseling Center. Above all else, Professor K. ensures that the process for dealing with conflicts is respectful of all involved.

\section{LESSONS LEARNED}

As a result of implementing this new team term project assignment in her Management and Organizational Behavior course and reflecting on what worked well and what needed further tweaking, Professor K. has identified three primary lessons she learned in the implementation process relating to 1) the non-textbook secondary sources students access in their research, 2) the team presentations, and 3) the team process for firing a team member.

First, despite enlisting a business reference librarian to train students in selecting and accessing credible secondary sources, many students defaulted to randomly searching the internet for information to use in their reports, resulting in their using sources that were unacceptable. Professor K. now believes it is important to restrict the sources for undergraduate students to a few (6-8) current news sources that are readily available to students but that the instructor also identifies as credible at least for the first report. If students find additional sources as they research for the first report that they would like to use, they can ask permission to use these additional sources on the next two reports. This process opens lines of communication with the instructor and keeps the students focused on finding credible sources. Professor $\mathrm{K}$. also suggests restricting the age of the information to 12-18 months in the assignment so the students will be reading about relatively current events for their company.

Secondly, anticipating that class sizes will continue to grow, Professor K. now sees that fewer oral reports may be necessary as a result of having more teams in the same amount of available class time. The team term project assignment can easily be restructured to having three written reports, only one of which is presented rather than all three. And the teams could select a spokesperson rather than all team members participating in the presentation to facilitate communicating the information to the class in a concise 
manner. The design of her team term project assignment is flexible enough, however, to make these changes as the circumstances (such as class size) change.

Thirdly, the new process for handling conflicts among students in teams, particularly the situations in which teams want to fire a member, resulted in fewer major interpersonal conflicts. Students seemed to be clearer about what was expected of them as a result of creating their own team rules. Teams used the rules to work out their issues, and they acted faster when problems arose. The rules became a bridge for open communications, and students used the same wording in their rules, in their e-mails regarding disciplinary actions, and in their peer evaluation feedback to fellow team mates. The rules allowed students to connect their performance expectations with observable behaviors and to focus on those observable behaviors rather than on personality conflicts. Students seemed to better recognize that their actions (or inactions) had significant consequences for their own well-being in the course, and having feedback coming from their peers that their behavior was unacceptable was generally surprising, shocking, and quite humbling. All of these combined led to higher student achievement.

\section{IMPROVEMENTS IN STUDENT ENGAGEMENT}

Professor K. designed this project with the primary goal of improving student engagement in the Management and Organizational Behavior course. In addition to this important outcome, however, the team project also encourages critical thinking and builds analytical skills that are transferable to many other contexts. It allows students to polish skills in performing independent research in secondary sources and in communicating what they have learned in that research succinctly in written and oral forms. And, importantly, the team project encourages students to apply the concepts discussed in the course by thinking about how their real-world companies are impacted by these topics.

Whereas before implementing the team project students typically attended around $80 \%$ of class meetings, after implementation students typically attended $85-90 \%$ of class meetings. Before the percentage of students failing the course was $11 \%$, and after the percentage with failing grades was $2.5 \%$. And before implementing the project, the percentage of students withdrawing from the course before the end of the semester was $6 \%$, but after implementation this dropped to $5 \%$.

Beyond these percentage changes, however, Professor K. noted after implementing this team project in the course that students came to identify with their teams over the semester ("We are Pepsico"). Students began to sit together as teams since they were allowed to do their oral presentations from their seats rather than the front of the classroom if they preferred. Before the class sessions began, many students started chatting with each other rather than being absorbed with something on their phones. During class, students contributed to the class discussions more frequently and seemed to be more comfortable in expressing themselves in class as a result of knowing their classmates better. They were more conscientious about attending class and more likely to voluntarily communicate reasons to Professor $\mathrm{K}$. when they missed a class. And students seemed to understand the material covered in the textbook and course better as a result of reading about the concepts in other, non-textbook sources in addition to the textbook. The students spent more time with the material and had more control over what they read and what they learned as a result of doing the additional research in the non-textbook secondary sources.

After implementing the team project Professor K. received feedback from students, submitted anonymously in the student evaluation process at the end of each semester, such as the following:

- "I very much like the group project. I learned a lot through it and met some really great individuals in the process."

- "I liked the group project. It was interesting to learn the information about the different companies."

- "In my opinion, the team interaction was the most beneficial part of the course."

- "The reports are excellent and do a perfect job of reflecting different chapters in the text book." 
- "I liked hearing real world examples of different types of management or how terms we are learning are applied in the real world during the team projects."

- "I enjoyed learning while working in my group. Wonderful experience."

- "My team did very well together. Everyone participated, communication was also great. This is the first time I did not have an issue with a team."

- "We have learned a lot from each other."

- "The project was nice because you were forced to think about the topics we've learned through a real-life perspective, rather than just some terms in a textbook."

- "The most beneficial has been the team projects, not only has it served as a means of meeting new people, but also just another way for me to study outside of class."

This evidence all supports Professor K.'s sense that implementing this new team project assignment accomplished what she set out to do: improve student engagement in a large class format.

\section{REFERENCES}

Brooks, C.M., \& Ammons, J.L. (2003). Free riding in group projects and the effects of timing, frequency, and specificity of criteria in peer assessments. Journal of Education for Business, 78(5), 268-272.

Chen, G., Donahue, L.M., \& Klimoski, R.J. (2004). Training undergraduates to work in organizational teams. Academy of Management Learning \& Education, 3(1), 27-40.

Curşeu, P.L., Schruijer, S.G.L., \& Fodor, O.C. (2017). Minority dissent and social acceptance in collaborative learning groups. Frontiers in Psychology, 8, 1-9.

Davison, H.K., Mishra, V., Bing, M.N., \& Frink, D.D. (2014). How individual performance affects variability of peer evaluations in classroom teams: A distributive justice perspective. Journal of Management Education, 38(1), 43-85.

Layton, R.A., Loughry, M.L., Ohland, M.W., \& Ricco, G.D. (2010). Design and validation of a webbased system for assigning members to teams using instructor-specified criteria. Advances in Engineering Education, 2(1), 1-28.

Loughry, M.L., Ohland, M.W., \& Woehr, D J. (2014). Assessing teamwork skills for assurance of learning using CATME team tools. Journal of Marketing Education, 36(1), 5-19.

Ohland, M.W., Loughry, M.L., Woehr, D.J., Bullard, L.G., Felder, R. M., Finelli, C.J., ... Schmucker, D.G. (2012). The comprehensive assessment of team member effectiveness: Development of a behaviorally anchored rating scale for self- and peer evaluation. Academy of Management Learning \& Education, 11(4), 609-630.

University of North Carolina Charlotte Office of Undergraduate Admissions. (2018). Niners by the Numbers. 